
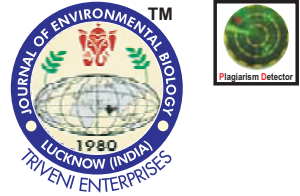

\title{
Biodegradation of perylene and benzo [ghi] perylene (5-6 rings) using yeast consortium : Kinetic study, enzyme analysis and degradation pathway
}

Authors Info

S.K. Mandal and N. Das*

Bioremediation Laboratory, School of Bio Sciences and Technology (SBST), VIT University, Vellore - 632 014, India

*Corresponding Author Email : nilanjana00@lycos.com

Key words

Benzo[ghi]perylene

Perylene

Microbial remediation

Yeast consortium

\section{Publication Info}

Paper received : 23.05.2016

Revised received : 29.11.2016

Re-revised received : 16.03.2017 Accepted : 08.08.2017

\section{Abstract}

Aim : The present work aims to demonstrate the ability of yeast consortium for degradation of perylene and benzo[ghi]perylene which may contribute towards the development of an appropriate in-situ bioremediation techniques.

Methodology : Degradation of perylene (five ring) and benzo[ghi]perylene (six ring) was evaluated using yeast consortia under optimized conditions. Rate of biodegradation was tested with various kinetic models and intermediate metabolites were identified by GC-MS and FTIR analysis. Involvement of enzymes viz., 1,2-dioxygenase, 2,3dioxygenase, catalase, laccase, lignin peroxidase and manganese peroxide were noted during PAHs degradation.

Results : The yeast consortium YCO2 (Hanseniaspora opuntiae NSO2, Debaryomyces hansenii NS03 and Hanseniaspora valbyensis NS04) degraded 67 $\%$ perylene at initial concentration $50 \mathrm{mg} \mathrm{l}^{-1}$, whereas YC04 (Rhodotorula sp. NS01, Debaryomyces hansenii NS03 and Hanseniaspora valbyensis NS04) degraded 60 $\%$ benzo[ghi]perylene at initial concentration $40 \mathrm{mg} \mathrm{l}^{-1}$ after 6 days. The consortium YC02 and YC04 exhibited best reaction by first order kinetics with half life period of 3.397 days and 4.218 days for degradation of perylene and benzo[ghi]perylene, respectively.

Interpretation : Based on the metabolites identified by GC-MS and FTIR analysis, possible pathways of perylene and benzo[ghi]perylene degradation were proposed. The results of present study revealed that application of yeast consortium can be a valuable approach towards remediation of high molecular weight $\mathrm{PAHs}$ having more benzene rings.

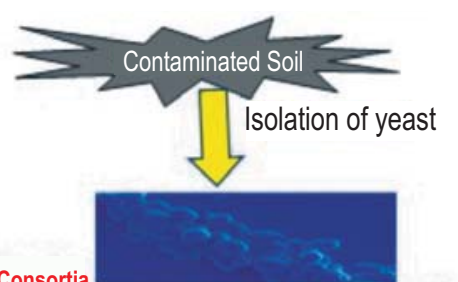

Yeast Consortia

- YC02 (Hanseniaspora opuntiae NS02, Debaryomyces hansenii NSO3, Hanseniaspora valbyensis NS04)

- YC04 (Rhodotorula sp. NS01, Debaryomyces hansenii NSO3, Hanseniaspora valbyensis NS04)

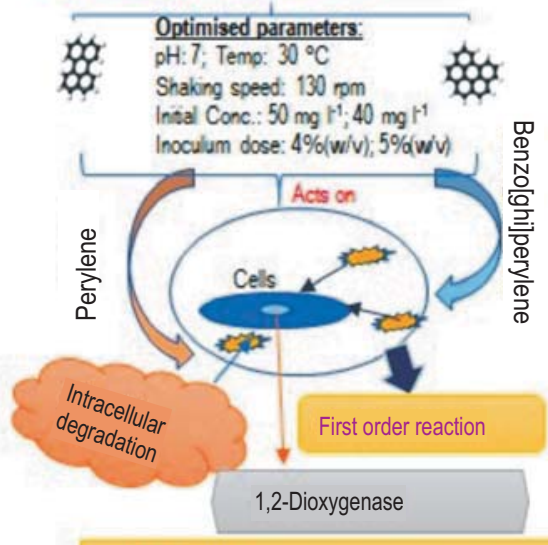

HMW PAHS

(perylene: $67 \%$ degradation

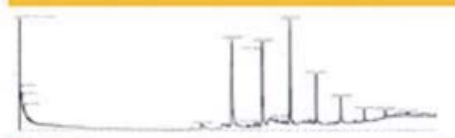

Gas Chromatogram-Mass Spectroscopy Benzo[ghi]perylene: $60 \%$ degradation 


\section{Introduction}

Polycyclic aromatic hydrocarbons (PAHs) are potentially mutagenic and carcinogenic substances found in soil, surface water and sediments. They are chemically very stable and cannot be degraded easily. PAHs contain one or more benzene rings, the higher the benzene rings, the molecule is more persistent (de Boer and Wagelmans, 2016). Generally, the heavier (4-, 5-, and 6-ring) PAHs are more persistent than the lighter (2- and 3-ring) PAHs and have greater carcinogenic and other chronic impact potential (Hesham et al., 2006).

Perylene is a high molecular weight polycyclic aromatic hydrocarbon (HMW PAH) compound having five benzene rings and reported as procarcinogen formed during the process of incomplete combustion of organic materials. It is phototoxic $\mathrm{PAH}$ (Irwin et al., 1997) and found in marine sediments (Slater et al., 2013); freshwater and river sediments (Fan et al., 2011) and terrestrial sediments (Itoh and Hanari, 2010; Marynowski et al., 2013). Benzo[ghi]perylene, another high molecular weight polycyclic aromatic hydrocarbon (HMW-PAH) compound having 6 benzene rings, is extremely recalcitrant to degradation (Zapien et al., 2009; Mohan et al., 2011) and known for carcinogenic, mutagenic and teratogenic properties (Luch, 2005).

Several physico-chemical techniques such as incineration, thermal desorption, soil washing etc., are used for reclamation of PAHs polluted soil. But these methods are not of choice because of high cost and legislation constraints. Compared to conventional techniques, microbial technology seems to be more efficient, cost effective and eco-friendly for remediation of PAHs contaminated area (Li et al., 2014). More reports are available on degradation of low molecular weight (LMW) PAHs compared to (HMW) PAHs. Though there are reports on degradation of perylene and benzo[ghi]perylene using fungi and yeast (Hesham et al., 2006; Silva et al., 2009; Winquist et al., 2014; Garcia-Delgado et al., 2015), detailed information on the mechanism of degradation, role of enzymes, degradation pathways are lacking. Therefore, the present work aimed to demonstrate the ability of yeast consortium elucidating the mechanism of degradation of perylene and benzo[ghi]perylene which may contribute towards the development of an appropriate in-situ bioremediation techniques.

\section{Materials and Methods}

Yeast consortium : In a previous study, four yeast strains were reported which were isolated from PAHs contaminated sites, Vellore, Tamil Nadu and identified as Rhodotorula sp. NS01, Hanseniaspora opuntiae NS02, Debaryomyces hansenii NS03 and Hanseniaspora valbyensis NSO4 using molecular techniques (Mandal et al., 2016). In the present study, each yeast consortium was formed by combining three identified yeast strains. Yeast consortia viz. YC01 (Rhodotorula sp. NS01, Hanseniaspora opuntiae NS02, Debaryomyces hansenii NS03); YC02
(Hanseniaspora opuntiae NS02, Debaryomyces hansenii NS03, Hanseniaspora valbyensis NS04); YC03 (Rhodotorula sp. NS01, Hanseniaspora opuntiae NSO2, Hanseniaspora valbyensis NS04) and YC04 (Rhodotorula sp. NS01, Debaryomyces hansenii NS03, Hanseniaspora valbyensis NS04) were developed and used for the degradation study.

Screening of perylene and benzo[ghi]perylene degrading yeast consortium : Yeast inoculums were prepared in yeast extract peptone dextrose broth containing yeast extract; $10 \mathrm{gl}^{-1}$, peptone; $20 \mathrm{gl}^{-1}$, dextrose; $20 \mathrm{~g} \mathrm{l}^{-1}$ and agar; $20 \mathrm{~g} \mathrm{l}^{-1}$ with perylene $\left(1.0 \mathrm{mg} \mathrm{l}^{-1}\right)$ and benzo[ghi]perylene $\left(1.0 \mathrm{mg} \mathrm{l}^{-1}\right)$. For acclimatization study, the yeast consortium culture was transferred into fresh sterile medium with an increasing concentration of 1.0 to $10.0 \mathrm{mg} \mathrm{l}^{-1}$, incubated at $28 \pm 2{ }^{\circ} \mathrm{C}$ on the rotary shaker at $120 \mathrm{rpm}$ for 5 days. To screen the potentiality of yeast consortium, yeast culture containing three yeast strains was suspended in mineral medium supplemented with perylene or benzo[ghi]perylene $\left(10.0 \mathrm{mgl}^{-1}\right)$ separately and incubated for 6 days. The cell suspensions were centrifuged at $8,400 \times \mathrm{g}$ for 10 min at regular interval. The pellets were washed in methanol separately to remove residue of perylene and benzo[ghi]perylene. Then it was transferred into pre-weighed perti dishes and dried to constant weight at $105^{\circ} \mathrm{C}$ for $45 \mathrm{~min}$ and dry weight of biomasses were calculated.

Optimization of growth parameters : To optimize the growth parameters during perylene or benzo[ghi]perylene degradation by yeast consortia, the flasks with $25 \mathrm{ml} \mathrm{MM}$ containing $10.0 \mathrm{mg} \mathrm{l}^{-1}$ perylene and benzo[ghi]perylene were inoculated with $1 \mathrm{ml}$ of YEPD broth culture of each yeast consortium (O.D. $\left.{ }_{6000}=0.1\right)$ and incubated at $30 \pm 2{ }^{\circ} \mathrm{C}$ on the rotary shaker for 6 days. The effect of $\mathrm{pH}(5-9)$, temperature $\left(10-40^{\circ} \mathrm{C}\right)$, shaking speed $(90-150 \mathrm{rpm})$, inoculum dosage $(2-5 \%)$, and initial perylene or benzo[ghi]perylene concentration (10-50 $\left.\mathrm{mg} \mathrm{l}^{-1}\right)$ during degradation were studied. During optimization of parameters, all others parameters were kept constant, except the optimizing parameter. Abiotic and biotic controls were maintained for each experiment. All the tests were conducted in triplicates.

Degradation of perylene and benzo[ghi]perylene : Experiments on perylene and benzo[ghi]perylene degradation were carried out in triplicates. Each flask was spiked with perylene $\left(50 \mathrm{mg} \mathrm{l}^{-1}\right)$ and benzo[ghi]perylene $\left(40 \mathrm{mgl}^{-1}\right)$ containing yeast consortium at optimized dosage. The culture broths were incubated in an orbital shaker $(130 \mathrm{rpm})$ for 6 days at $30^{\circ} \mathrm{C}$. The flasks were withdrawn at particular intervals for analysis of residual perylene and benzo[ghi]perylene and uninoculated culture flasks which were kept as control. The residual perylene and benzo[ghi]perylene in the culture medium was calculated.

Kinetics of perylene and benzo[ghi]perylene degradation : Degradation kinetics for the yeast consortia were performed in triplicates. The zero order (Wang et al., 2002), first order (Agarry et al., 2013) and second order (Capellos and Bielski, 1972) 

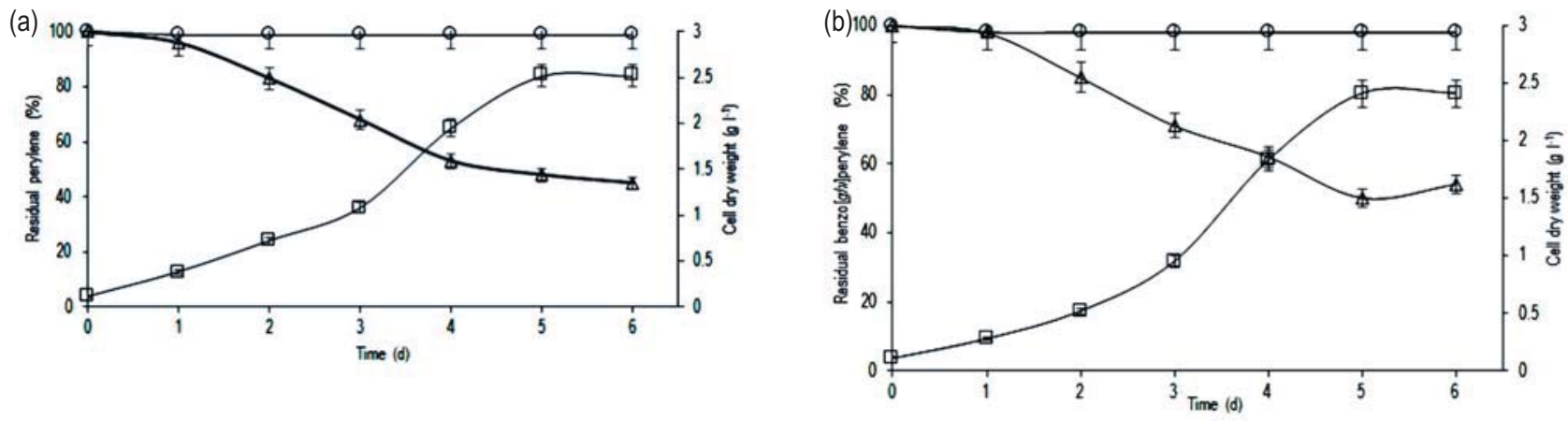

Fig. 1: (a) Growth curve of yeast consortium, YC02 in mineral broth and perylene biodegradation (\%), abiotic control (0), cell dry weight ( $\square$ ) and residual perylene concentration $(\Delta)$. (b) Growth curve of yeast consortium, YC04 in mineral broth and benzo[ghi]perylene biodegradation ( $\%)$, abiotic control (0), cell dry weight $(\square)$ and residual benzo[ghi]perylene concentration $(\Delta)$.

kinetics models were used to define the degradation of perylene and benzo[ghi]perylene in mineral medium.

Enzyme assays: Yeast cells grown in the presence of perylene and benzo[ghi]perylene were harvested at different time intervals $(0,2,4$ and $6 \mathrm{~d})$ and were grown in mineral medium with $50 \mathrm{mg} \mathrm{I}^{-1}$ perylene and $40 \mathrm{mg} \mathrm{I}^{-1}$ benzo[ghi]perylene as carbon and energy source. The cultures were centrifuged (10,000 rpm, $15 \mathrm{~min})$ at 25 ${ }^{\circ} \mathrm{C}$ and rapidly washed 3 times with $50 \mathrm{mM}$ phosphate buffer (pH 7.0). Cells were disintegrated with a probe-type sonic oscillator for $10 \mathrm{~min}$. The extract was centrifuged at $10,000 \mathrm{rpm}$ at $4{ }^{\circ} \mathrm{C}$ for $30 \mathrm{~min}$ to remove whole cells and large debris and the collected supernatant was used immediately for the enzyme assays. Various enzymes viz., 1,2-dioxygenase (Dorn and Knackmuss, 1978), 2,3-dioxygenase (Bayly et al., 1966), catalase (Flores et al., 2014), laccase (Arora and Sindhu, 1985), lignin peroxidase (Li et al., 2009) and manganese peroxidase (MnP) (Annudurai et al., 2000) activities were assayed following the standard protocols collecting the samples at regular intervals of $0,2,4$ and 6 days.

Characterization of degraded products by GC-MS and FT-IR analysis : Residual perylene or benzo[ghi]perylene and degraded products were determined by GC-MS chromatography and FTIR analysis. At regular intervals of $0,2,4$ and 6 days of incubation, flasks were withdrawn for the analysis of degraded products. The residual perylene or benzo[ghi]perylene and also degraded products were extracted and analysed using GC-MS following the method of Arulazhagan et al. (2010). Standards from Sigma Aldrich and Supleco were used for perylene and benzo[ghi]perylene, respectively. GC-MS library search was used to confirm the metabolites without standards as available in the National Institute of Standard Technology (NIST) library, USA.

The FTIR spectra of perylene or benzo[ghi]perylene and degraded products were used to determine the vibrational frequency changes in the functional groups. IR spectroscopy was investigated with an IR affinity-1 FT-IR spectrophotometer (Shimadzu) using KBr pellets. The range of scanning was kept between 4,000 to $500 \mathrm{~cm}^{-1}$ and the spectrum resolution was $4 \mathrm{~cm}^{-1}$.

\section{Results and Discussion}

Yeast consortia were screened for perylene and benzo[ghi] perylene degradation as sole carbon and energy source (Fig. 1). Based on the screening results, it was found that the yeast consortium, YC02 showed maximum perylene degradation (55\%), followed by YC01 (50\%), YC03 (48 \%) and YC04 (45\%). In case of benzo[ghi]perylene, YC04 was found to show maximum degradation (46\%), followed by YC01 (40\%), YC02 (33\%) and YC03 (38\%). These results are consistent with the results obtained by others researches, who found that some fungal and bacterial strains preferred particular type of PAH as sole carbon source (Arulazhagan et al., 2014; Balaji et al., 2014; Alrumman et al., 2016; Zafra et al., 2017).

Yeast consortium, YC02 showed maximum degradation efficiency and cell biomass at $\mathrm{pH} 7$, temperature at $30^{\circ} \mathrm{C}$, shaking speed at $130 \mathrm{rpm}$, inoculum dosage of $4 \%$ and initial perylene concentration of $50 \mathrm{mg} \mathrm{l}^{-1}$. Yeast consortium, YC04 showed maximum degradation efficiency and cell biomass at $\mathrm{pH} 7$, temperature at $30^{\circ} \mathrm{C}$, shaking speed at $130 \mathrm{rpm}$, inoculum dosage of $5 \%$ and initial benzo[ghi]perylene concentration of 40 $\mathrm{mgl}^{-1}$ (Fig. $\left.2 \mathrm{a}, \mathrm{b}\right)$. The yeast consortia were able to remove $50 \mathrm{mg}$ $\mathrm{I}^{-1}$ initial concentration of perylene in the following order: $\mathrm{YCO} 2$ $(67.0 \%)>Y C 01(62.0 \%)>Y C 03(59.0 \%)>Y C 04(56.0 \%)$ and 40 $\mathrm{mg} \mathrm{I}^{-1}$ initial concentration of benzo[ghi]perylene in the order: YC04 $(60.0 \%)>$ YC01 $(55.0 \%)>$ YC02 $(53.0 \%)>$ YC03 $(48.0 \%)$, after 6 days of incubation period. Hesham et al. (2006) reported $70 \%$ degradation of perylene at concentration of $6.03 \mathrm{mg} \mathrm{kg}^{-1}$ and $78 \%$ degradation of benzo[ghi]perylene at concentration of 2.17 $\mathrm{mg} \mathrm{kg}^{-1}$ in 42 day using yeast consortium (Candida maltose, Pichia anomala, Sporidiobolus salmonicolor, Pichia guilliermondii and Rhodotorula dairenensis). Therefore, yeast consortia used in the present study showed better performance in terms of concentration of perylene and benzo[ghi]perylene, as well as 
Table 1 : Kinetics parameters for the degradation of perylene $\left(50 \mathrm{mg} \mathrm{l}^{-1}\right)$ and benzo[ghi]perylene $\left(40 \mathrm{mg} \mathrm{l}^{-1}\right)$ by yeast consortium YC02 and YC04

\begin{tabular}{llll}
\hline Kinetic model & Parameters & YC02 (Perylene) & YC04(Benzo[ghi]perylene) \\
\hline Zero order & Regression Equation & $\mathrm{C}_{\mathrm{t}}=-6.125 \mathrm{t}+49.875$ & $\mathrm{C}_{\mathrm{t}}=-4.393 \mathrm{t}+41.79$ \\
$\mathrm{C}_{\mathrm{t}}-\mathrm{C}_{0}=\mathrm{Kt}$ & $\mathrm{K}\left(\mathrm{d}^{-1}\right)$ & 6.125 & 4.393 \\
$\mathrm{~T}_{1 / 2}=\mathrm{C}_{0} / 2 \mathrm{~K}_{0}$ & $\mathrm{~T}_{1 / 2}$ & 4.082 & 4.553 \\
& $\mathrm{R}^{2}$ & 0.969 & 0.968 \\
First order & Regression Equation & $\operatorname{lnC}_{\mathrm{t}}=-0.204 \mathrm{t}+3.980$ & $\operatorname{lnC}_{\mathrm{t}}=-0.164 \mathrm{t}+3.7711$ \\
$\ln \mathrm{C}_{\mathrm{t}}=\mathrm{K}_{\mathrm{t}} \mathrm{t}+\ln \mathrm{C}_{0}$ & $\mathrm{~K}\left(\mathrm{~d}^{-1}\right)$ & 0.204 & 0.164 \\
$\mathrm{~T}_{1 / 2}=\ln 2 / \mathrm{K}_{1}$ & $\mathrm{~T}_{1 / 2}$ & 3.397 & 4.218 \\
Second order & $\mathrm{R}^{2}$ & 0.974 & 0.972 \\
$1 / \mathrm{C}_{\mathrm{t}}=1 / \mathrm{C}_{0}+\mathrm{K}_{2} \mathrm{t}$ & Regression Equation & $11 \mathrm{C}_{\mathrm{t}}=0.0075 \mathrm{t}+0.0152$ & $11 \mathrm{C}_{\mathrm{t}}=0.0065 \mathrm{t}+0.0203$ \\
$\mathrm{~T}_{1 / 2}=1 / \mathrm{C}_{0} \mathrm{~K}_{2}$ & $\mathrm{~K}\left(\mathrm{~d}^{-1}\right)$ & 0.0075 & 0.0065 \\
& $\mathrm{~T}_{1 / 2}$ & 92.4 & 106.615 \\
\hline
\end{tabular}

$R^{2}=$ Regression coefficient; $K=$ Degradation rate constant; $T_{1 / 2}=$ Half life period

number of days needed for biodegradation. Based on the optimization study, the yeast consortium, YC02 for perylene and YC04 for benzo[ghi]perylene were selected for the further degradation study.

The kinetic data on degradation of perylene (50 $\left.\mathrm{mg} \mathrm{l}^{-1}\right)$ and benzo[ghi]perylene (40 $\left.\mathrm{mg} \mathrm{l}^{-1}\right)$ were fitted with three mathematical kinetic models (Fig.3a, b). The results showed that the degradation kinetics of perylene and benzo[ghi]perylene by yeast consortium, YC02 and YC04 can be described well by first order reaction kinetics with respect to the aqueous concentration of perylene and benzo[ghi]perylene. The highest regression coefficient $\left(R^{2}\right)$ values of 0.974 and 0.972 in first order kinetic model indicated that the degradation kinetics of perylene and benzo[ghi]perylene by yeast consortium, YC02 and YC04 follows first order reactions (Table 1). This implied that the removal of perylene and benzo[ghi]perylene by yeast consortia were time dependant process and degradation rate was directly proportional to substrate concentration (Deng et al., 2012; Jin et al., 2017). The calculated degradation rate constant $\mathrm{K}$ was 0.204 $\mathrm{d}^{-1}$ and the theoretical half-life of perylene was 3.397 days, whereas calculated degradation rate constant K was $0.164 \mathrm{~d}^{-1}$ and the theoretical half-life of benzo[ghi]perylene was 4.218 days. It was noted that higher the biodegradation rate constant, faster is the rate of biodegradation, and consequently the half-life times are lower. The calculated half-life of perylene and benzo[ghi]perylene, in the present study, was quite less.

On the initial phase of perylene as well as benzo[ghi]perylene breakdown, 1,2-dioxygenase showed profound activity both in the supernatant and cell lysate, whereas the reverse trend was observed in other degradative enzymes studied. Catalase, lignin peroxidase (LiP) and manganese peroxide $(\mathrm{MnP})$ activity was found to be less on 2 nd day, but was increased on $4^{\text {th }}$ day and further decreased over incubation time. The activity of all the enzymes viz., catalase, laccase, lignin peroxidase, manganese peroxide, 1,2-dioxygenase and 2,3dioxygenase were more in cell lysate than in the cell supernatant, which implicated the intracellular nature of these enzymes (Fig. 4a, b). Dioxygenase helps in ring-cleavage as well as decyclize the aromatic compounds which allows the products to be channelled in the metabolic pathways of cells (Pérez-Pantoja et al., 2010). Initial ring-cleavage of other HMW PAH (benzo[a]pyrene) by lignolytic enzymes such as 1,2-dioxygenase and 2,3-dioxygenase in $P$. ostreatus PO-3 has been reported by Mishra and Singh (2014).

Six possible metabolites were identified using NIST library identification program (Fig. 5a). Perylene, which eluded with a retention time of $26.3 \mathrm{~min}$., was gradually degraded. Sample withdrawn on the day 2, indicated the presence of two different new possible intermediate peaks that eluted at 25.4 and $19.8 \mathrm{~min}$ and identified as benzeneacetic acid, 2-tridecyl ester (BATDE) and 1,2,4-benzenetric carboxylic acid 1,2dimethyl ester (1,2,4-BCADME), both of which were detected on the day 4 as well, indicating that they were formed during the initial phase of degradation and were then transformed onto other compounds for further degradation. On $2^{\text {nd }}$ day, the intensity of parent peak of perylene was reduced compared to parent compound. While another two apparent metabolites that were eluted at 21.4 and 15.2 min were seen on the 4th day of incubation and was confirmed to be hexanoic acid, 2phenylethyl ester (HA,2-PEE) and butanoic acid, 2-methyl-2pheyl ethyl ester (BA,2-MPEE), respectively, according to the NIST library. The intensity of perylene on $4^{\text {th }}$ day was reduced compared to $2^{\text {nd }}$ day. On $6^{\text {th }}$ day, two more new degraded products, eluted at 17.3 and $12.5 \mathrm{~min}$, were identified as npropyl decyl ether (n-PDE) and propanoic acid, 2-methyl-2ethyl-3-hydroxyhexyl ester (2-M-2-E-3-HHE), respectively. The parent compound intensity was reduced along with other newly degraded products which confirmed perylene degradation by the yeast consortium, YC02. 

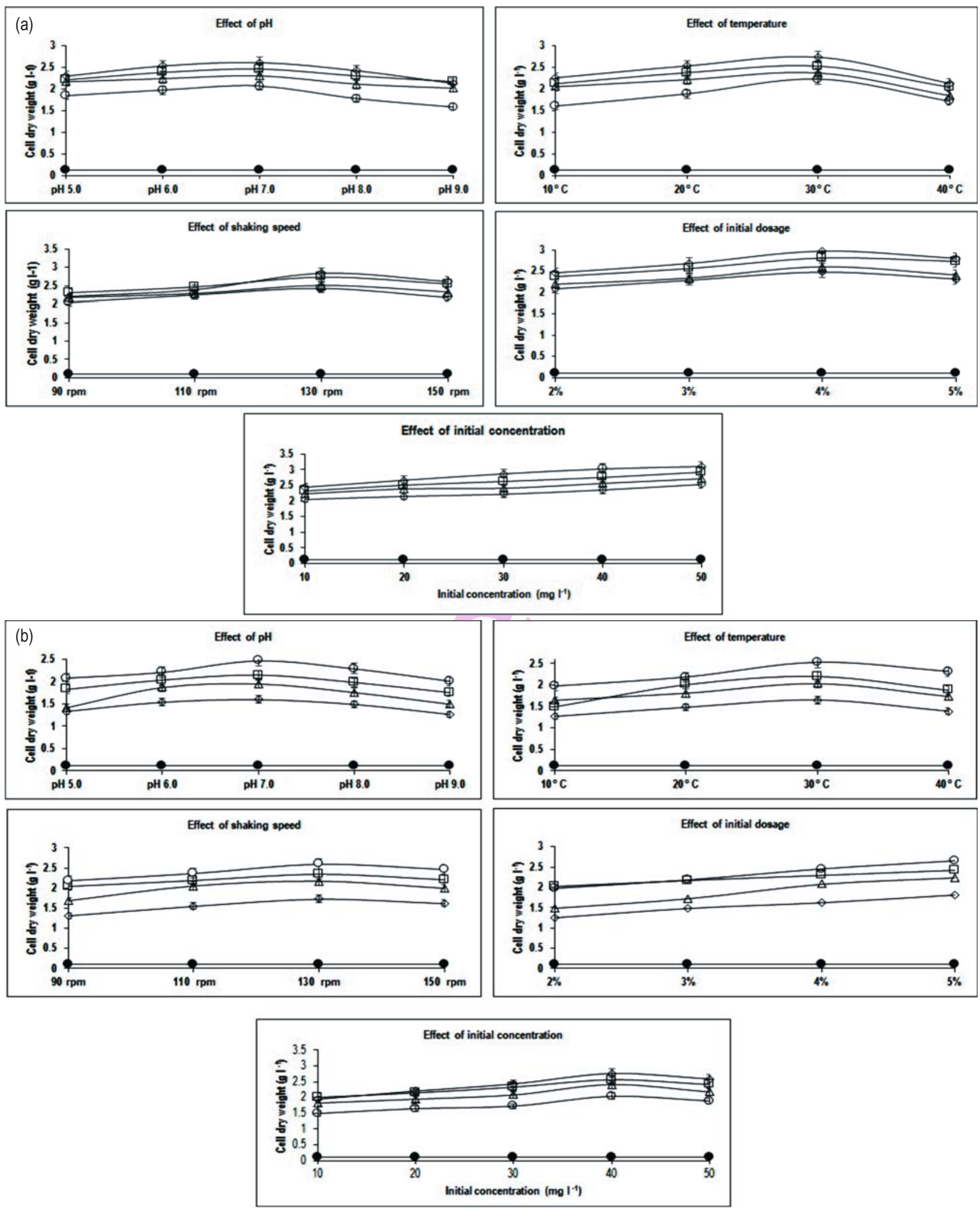

Fig. 2: Optimization of growth parameters for biodegradation study in MM with (a) perylene and (b) benzo[ghi]perylene by different yeast consortia such as $\mathrm{YC} 01(\square), \mathrm{YC02}(0), \mathrm{Yc03}(\Delta), \mathrm{YCO} 4(\diamond)$ and abiotic control $(\bullet)$. The effect of pH $(5.0,6.0,7.0,8.0$ and 9.0$)$, temperature $\left(10^{\circ} \mathrm{C}, 20^{\circ} \mathrm{C}, 30^{\circ} \mathrm{C}\right.$ and 40 ${ }^{\circ} \mathrm{C}$ ), shaking speed (90 rpm, $110 \mathrm{rpm}, 130 \mathrm{rpm}$ and $\left.150 \mathrm{rpm}\right)$, inoculums dosage with weight by volume percentage $(2 \%, 3 \%, 4 \%$ and $5 \%$ ) and initial perylene as well as benzo[ghi]perylene concentration $\left(10 \mathrm{mg} \mathrm{l}^{-1}, 20 \mathrm{mgl}^{-1}, 30 \mathrm{mgl}^{-1}, 40 \mathrm{mgl}^{-1}\right.$ and $\left.50 \mathrm{mgl}^{-1}\right)$ were evaluated for the period of 6 day 

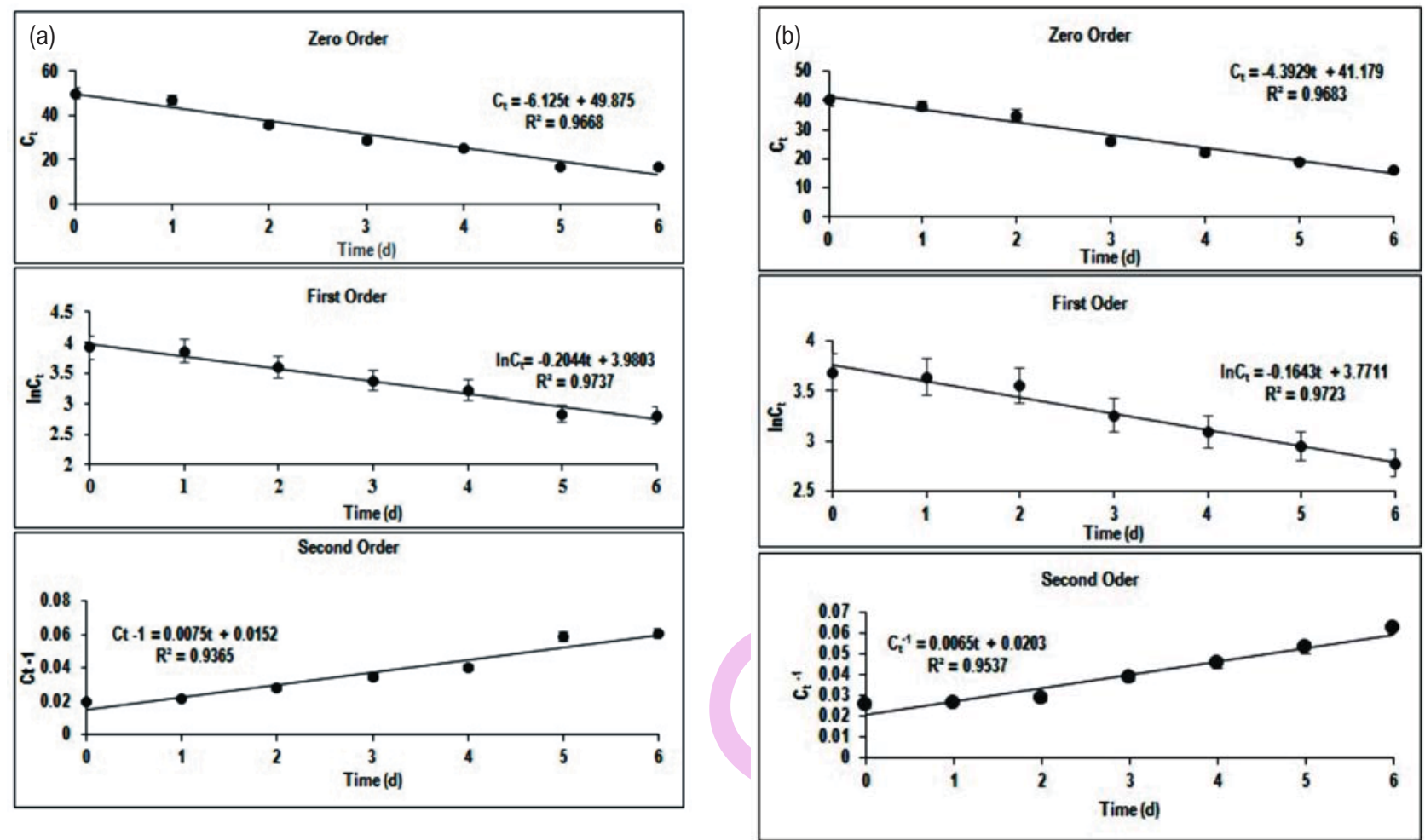

Fig. 3 : Kinetics models for biodegradation of (a) perylene by yeast consortium, YC02 and (b) benzo[ghi]perylene by yeast consortium, YC04 with zero order, first order and second order
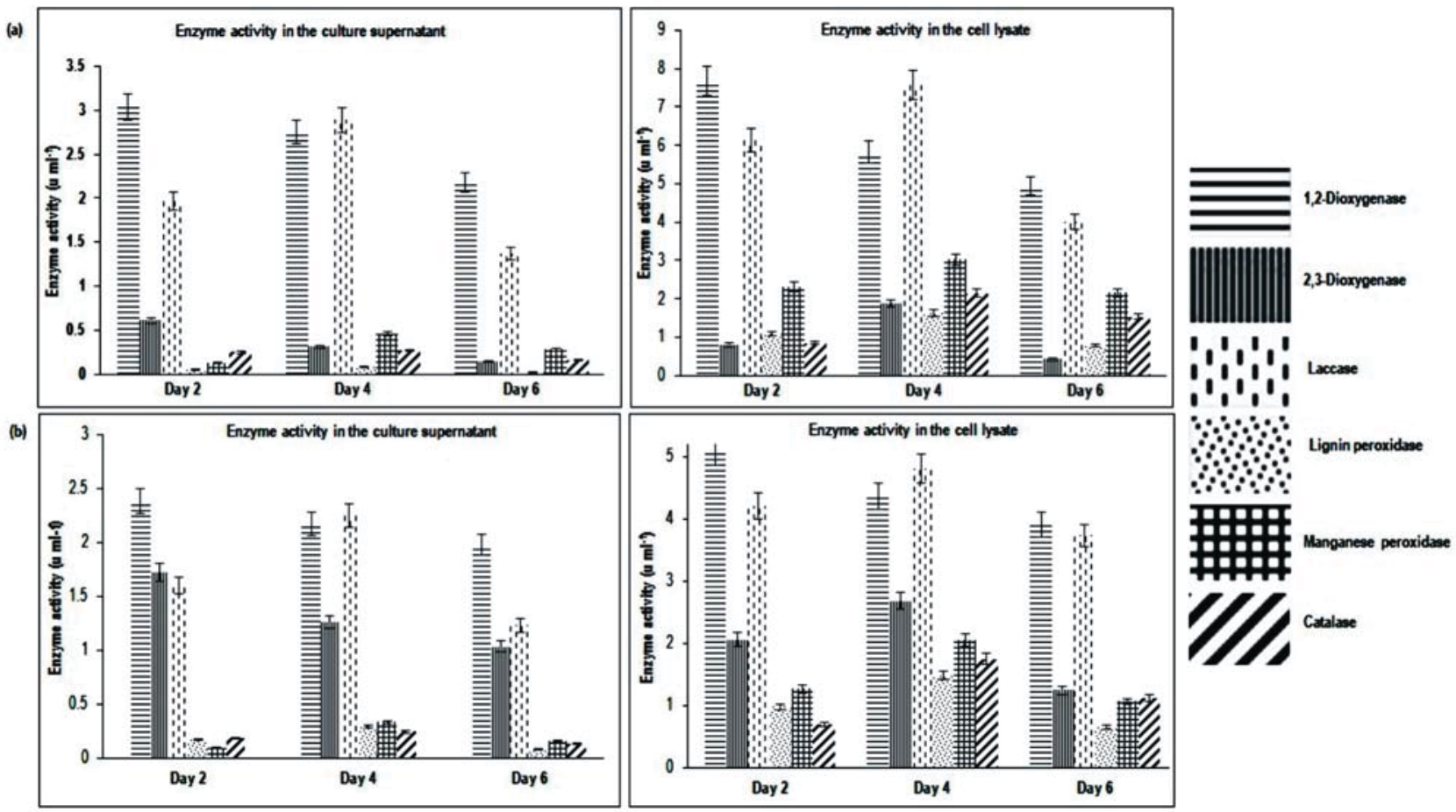

Fig. 4 : Enzyme activities $\left(\mathrm{U} \mathrm{ml}^{-1}\right)$ of (a)perylene degradation by yeast consortium, YC02 (b) benzo[ghi]perylene degradation by yeast consortium, YC04 in the culture supernatant and cell free extracts 

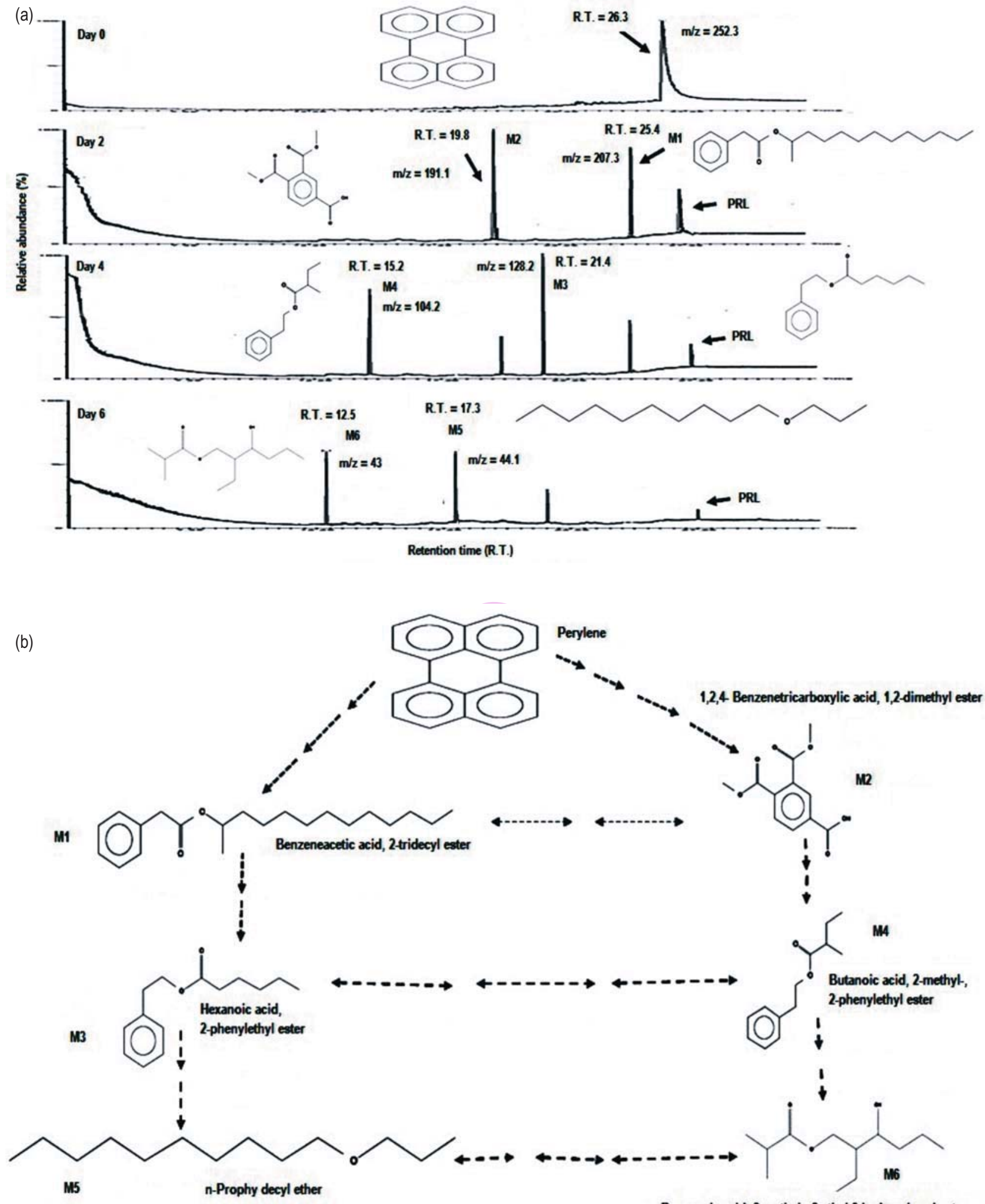

Fig. 5 : (a) GC-MS analysis of perylene and its biodegraded metabolites by yeast consortium, YC02 at 2, 4 and 6 d. (b) Proposed perylene biodegradation pathway by yeast consortium, YC02. The doted arrows represent transient products, which were not be detected by GC-MS analysis 


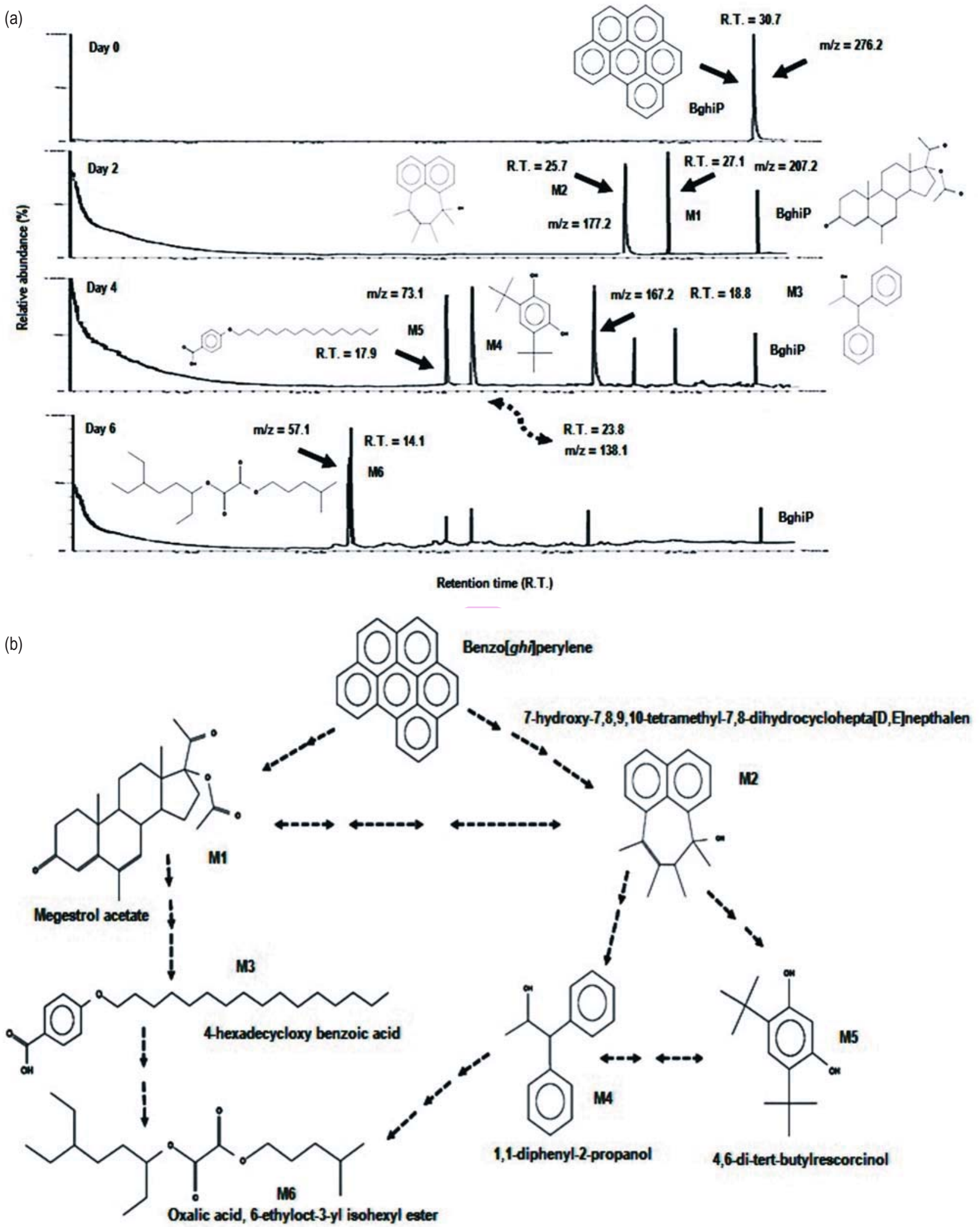

Fig. 6 : (a) GC-MS analysis of benzo[ghi]perylene and its biodegraded metabolites by yeast consortium, YC04 at 2, 4 and 6 d. (b) Proposed benzo[ghi]perylene biodegradation pathway by yeast consortium, YC04. The doted arrows represent transient products, which were not be detected by GC-MS analysis 


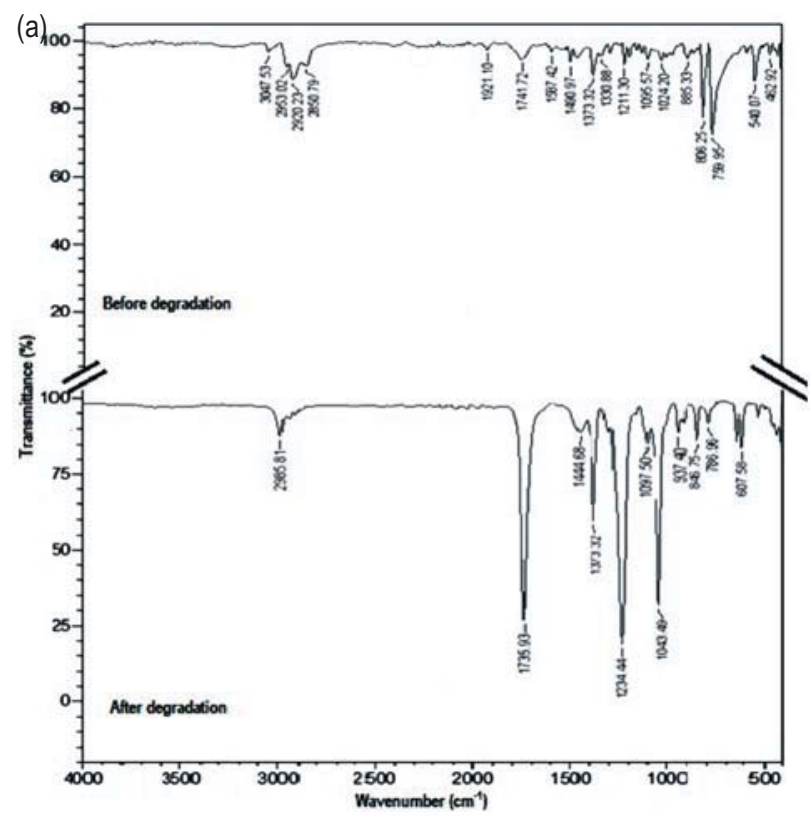

(b)

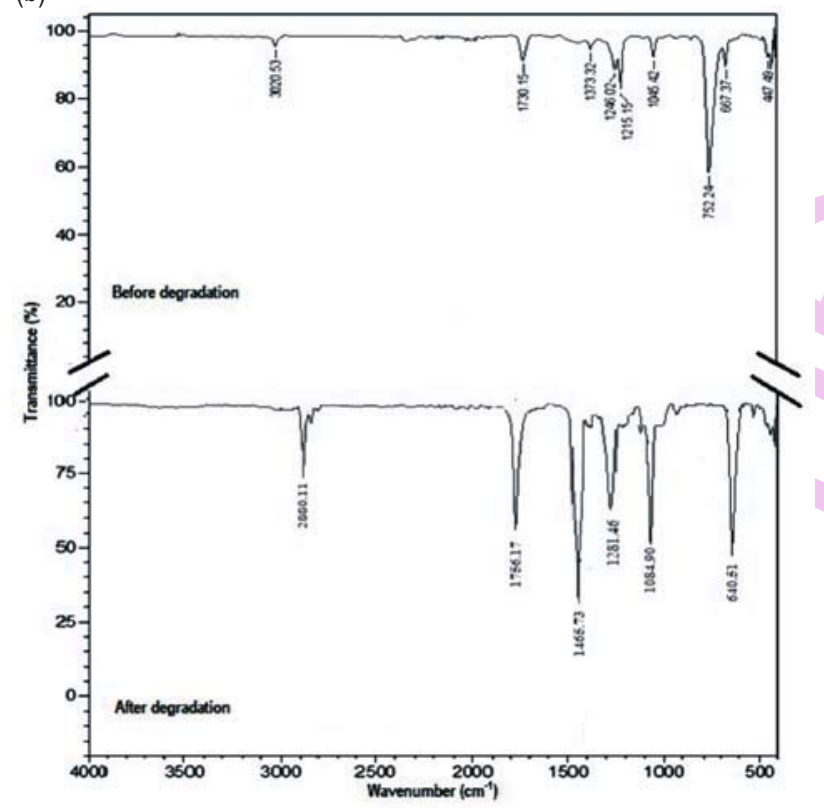

Fig. 7 : FTIR analysis of (a) perylene before and after degradation by yeast consortium, YC02 and (b) benzo[ghi]perylene before and after degradation by yeast consortium, $\mathrm{YCO} 4$ after 6 days

Based on the identified degraded products, a possible degradation pathway of perylene was proposed (Fig. $5 b$ ). The parent compound, perylene $(\mathrm{m} / \mathrm{z}=252.3)$ was initiated and gave rise to BATDE $(\mathrm{m} / \mathrm{z}=207.3)$ and $1,2,4-B C A D M E(\mathrm{~m} / \mathrm{z}=191.1)$. BATDE was further degraded giving rise to HA,2-PEE $(\mathrm{m} / \mathrm{z}=$ 128.2), whereas 1,2,4-BCADME gave rise to BA,2-MPEE $(\mathrm{m} / \mathrm{z}=$ 104.2) in which both compounds reduced the carbon chain length. The degradation pathway proceeded further, while HA,2-
PEE gave rise to a transient metabolite, $n-P D E(m / z=44.1)$ and BA,2-MPEE gave rise to 2-M-2-E-3-HHE (m/z = 43).

Benzo[ghi]perylene, which eluted with a retention time of 30.7 min, was gradually degraded into infinitesimal quantities (Fig. 6a). Sample withdrawn on day 2 indicated the presence of two different new possible intermediate peaks at 27.1 and 25.7 min and identified as megestrol acetate (ME) and 7-hydroxy7,8,9,10-tetramethyl-7,8-dihydrocyclohepta[D,E]nephthalen(7H-7,8,9,10-TM-7,8-DCDEN), both of which were detected on day 4 as well indicating that they were formed during the initial phase of degradation and were then transformed into other compounds for further degradation. On $2^{\text {nd }}$ day, the intensity of parent peak of benzo[ghi]perylene was reduced. While another three apparent metabolites that were eluted at $18.8,23.8$ and 17.9 min were seen on the $4^{\text {th }}$ day of incubation and was confirmed to be 4hexadecyclobenzenoic acid (4-HCBA), 1,1-diphenyl-2-propanol (1,1-DP-2-P) and 4,6-di-tert-butylrescorinol (4,6-D-T-BR), respectively, according to the NIST library. The intensity of benzo[ghi]perylene on $4^{\text {th }}$ day was reduced compared to $2^{\text {nd }}$ day. On the 6th day, a new degraded product eluted at 14.1 min was identified as oxalic acid, 6-ethyloct-3-yl isohexyl ester (OA,6-EO3 YIE). The parent compound intensity was reduced compared to $4^{\text {th }}$ day along with other newly degraded products which confirmed that benzo[ghi]perylene was degraded by the yeast consortium, YC04.

The degradation of parent compound, benzo[ghi] perylene $(\mathrm{m} / \mathrm{z}=276.2)$ was initiated to form, $M E(\mathrm{~m} / \mathrm{z}=207.2)$ and 7-H-7,8,9,10-TM-7, 8-DCHDEN ( $\mathrm{m} / \mathrm{z}=177.2)$. Further by multi step reduction, 4 -HCBA $(\mathrm{m} / \mathrm{z}=138.1)$ was formed which was reduced to OA,6-EO-3YIE $(\mathrm{m} / \mathrm{z}=57.9)$. The degradation pathway proceeded further, while 7-H-7,8,9,10-TM-7, 8-DCHDEN gave rise to transient metabolites, 1,1-DP-2-P $(\mathrm{m} / \mathrm{z}=167.2)$ and 4,6-D$\mathrm{T}-\mathrm{BR}(\mathrm{m} / \mathrm{z}=73.1)$ in which carbon rings were reduced (Fig. 6b). Meng et al. (2014) reported that degradation of PAHs may be enhanced with appropriate concentration of the metabolites.

FTIR spectra of control perylene (Fig.7a) showed the charactereristic absorption peaks at $3047 \mathrm{~cm}^{-1}(=\mathrm{CH}$ stretch in aromatic rings), $2850.79-2953.02 \mathrm{~cm}^{-1}$ (C-H stretching in cyclic ring), $1741.72-1921.1 \mathrm{~cm}^{-1}$ (weak overtone and combination bands in aromatic compounds), 1490.97-1587.42 (variable aromatic ring stretching), $759.75-885.33 \mathrm{~cm}^{-1}$ (strong out of plane $\mathrm{CH}$ deformations in aromatic compounds) and $462.92-540.07 \mathrm{~cm}^{-1}$ (ring deformations in aromatic compounds). The second spectra illustrated, degraded perylene products by yeast consortium, YC02 showed a presence of $2985.81 \mathrm{~cm}^{-1}$ showed the strong $\mathrm{CH}$ stretch in methyl groups. Sharp absorption peak of $1735.93 \mathrm{~cm}^{-1}$ (very strong $\mathrm{C}=0$ stretch in esters groups), $1373.32 \mathrm{~cm}^{-1}$ (medium $\mathrm{CH}_{3}$ deformations in isopropyl groups), $1234.44 \mathrm{~cm}^{-1}$ (varies from strong to very strong $\mathrm{C}-\mathrm{O}-\mathrm{C}$ stretch in ethers and also in esters groups), $1043.49 \mathrm{~cm}^{-1}$ (strong $\mathrm{C}-\mathrm{O}$ stretch in $\mathrm{CH}-\mathrm{OH}$ in cyclic alcohols) and $607.58 \mathrm{~cm}^{-1}$ (to strong $\mathrm{O}-\mathrm{C}=\mathrm{O}$ bending in carboxylic acids). 
FTIR spectra of control benzo[ghi]perylene (Fig.7b) showed distinctive absorption peaks at $3020.25 \mathrm{~cm}^{-1}$ (C-H stretch in aromatic rings), $1730.15 \mathrm{~cm}^{-1}$ (weak overtone and combination bands in aromatic compounds), $752.24 \mathrm{~cm}^{-1}$ (strong out of plane $\mathrm{CH}$ deformations in aromatic compounds), 667.37 (strong $\mathrm{CH}$ out of plan deformations in cis disubstituted alkenes) and $447.35 \mathrm{~cm}^{-1}$ (medium-strong ring deformations in aromatic compounds). The second spectra illustrated, degraded benzo[ghi]perylene products by yeast consortium, YCO4 showed a presence of $2880.11 \mathrm{~cm}^{-1}$ showed the presence of medium $\mathrm{CH}$ stretch in methyl groups in degraded products. Sharp absorption peak of $1756.17 \mathrm{~cm}^{-1}$ (strong $\mathrm{C}=0$ stretch in esters groups), $1465.73 \mathrm{~cm}^{-1}$ (medium $\mathrm{CH}_{2}$ deformations in alkyl groups), $1281.46 \mathrm{~cm}^{-1}$ (strong $\mathrm{C}-\mathrm{O}-\mathrm{C}$ stretch in ethers and also in esters groups) and 1084.90 $\mathrm{cm}^{-1}$ (strong $\mathrm{C}-\mathrm{O}$ stretch in $\mathrm{CH}-\mathrm{OH}$ in cyclic alcohols and 640.70 $\mathrm{cm}^{-1}$ (strong $\mathrm{O}-\mathrm{C}=\mathrm{O}$ bending in carboxylic acids).

In the present study, out of four yeast consortia, two consortia (YCO2 and YC04) were demonstrated as potential degrader of perylene and benzo[ghi]perylene in very less time period (6d). The potentiality of these two yeast consortia looks promising for the application in bioremediation technologies towards removal of high molecular weight polycyclic aromatic hydrocarbons (HMW PAHs) having five or six benzene rings.

\section{Acknowledgments}

We thank SAS, VIT University, Vellore for helping us in GC-MS and FTIR analysis. Financial assistance and laboratory facilities provided by VIT University, Vellore, Tamil Nadu, India is acknowledged.

\section{References}

Agarry, S.E., M.O. Aremu and O.A. Aworanti: Kinetic modelling and halflife study on enhanced soil bioremediation of bonny light crude oil amended with crop and animal-derived organic wastes. J. Pet. Environ. Biotechnol., doi:10.4172/2157-7463.1000137 (online) (2013).

Alrumman, S.A., A.E.L. Hesham and S.A. Alamri: Isolation, fingerprinting and genetic identification of indigenous PAHs degrading bacteria from oil-polluted soils. J. Environ. Bio., 37, 75-81 (2016).

Annadurai, G., R. Babu, G. Nagarajan and K. Ragu: Use of Box-Behnken design of experiments in the production of manganese peroxidase by Phanerochaete chrysosporium (MTCC 767) and decolorization of crystal violet. Biopro. Eng., 23, 715-719(2000).

Arora, D.S. and D.K. Sandhu: Laccase production and wood degradation by a white-rot fungus Daedalea flavida. Enz. Microbiol. Techn., 7, 405-408 (1985).

Arulazhagan, P., C. Sivaraman, S.A. Kumar, M. Aslam and J.R. Banu: Co-metabolic degradation of benzo(e)pyrene by halophilic bacterial consortium at different saline conditions. J. Environ. Bio., 35, 445-452, (2014).

Arulazhagan, P., N. Vasudevan and I.T. Yeom: Biodegradation of polycyclic aromatic hydrocarbon by a halotolerant bacterial consortium isolated from marine environment. Int. J. Environ. Sci. Tech., 7, 639-652 (2010).
Balaji, V., P. Arulazhagan and P. Ebenezer: Enzymatic bioremediation of polyaromatic hydrocarbons by fungal consortia enriched from petroleum contaminated soil and oil seeds. J. Environ. Bio., 35, 521-529 (2014).

Bayly, R.C., S. Dagley and D.T. Gibson: The metabolism of cresols by species of Pseudomonas. Biochem. J., 101, 293-301 (1966).

Capellos, C. and B.H. Bielski: Kinetic systems: mathematical description of chemical kinetics in solution. Wiley-Inter science, New York, USA(1972).

de Boer, J. and M. Wagelmans: Polycyclic aromatic hydrocarbons in soil - practical options for remediation. Clean Soil Air Water, 44, 648$653(2016)$.

Deng, L., Y. Ren and C. Wei: Pyrene degradation by Pseudomonas sp. and Burkholderia sp. enriched from coking wastewater sludge. J. Environ. Sci. Hlth., A, 47, 1984-1991 (2012).

Dorn, E. and H.J. Knackmus: Chemical structure and biodegradability of halogenated aromatic compounds: substituted effects on 1,2dioxygenation of catechol. Biochem. J., 174, 85-94 (1978).

Fan, C.W., J. Shiue, C.Y. Wu and C.Y. Wu: Perylene dominance in sediments from a subtropical high mountain lake. Org. Geochem., 42, 116-119 (2011).

Flores, R.V.G., E.P.S. Ceniceros, R.D.L. Gámez, C.B. García, J.L.M. Hernández, G.G. Lozano, C.N. Aguilar and A. Ilyina: Production and partial characterization of glucose oxidase and catalase from xerophytic strain of Aspergillus niger. Afri. J. Microbiol. Res., 8, 2788-2800 (2014).

García-Delgado, C., I. Alfaro-Barta and E. Eymar: Combination of biochar amendment and mycoremediation for polycyclic aromatic hydrocarbons immobilization and biodegradation in creosotecontaminated soil. J. Hazard. Mater., 285, 259-266 (2015).

Hadibarata, T. and R.A. Kristanti: Identification of metabolites from benzo[a]pyrene oxidation by ligninolytic enzymes of Polyporus sp. S133. J. Environ. Manage., 111, 115-119 (2012).

Hesham, A.E.L., S. Khan, X.C. Liu, Y. Zhang, Z. Wang and M. Yang: Application of PCR-DGGE to analyse the yeast population dynamics in slurry reactors during degradation of polycyclic aromatic hydrocarbons in weathered oil. Yeast, 23, 879-887 (2006).

Itoh, N. and N. Hanari: Possible precursor of perylene in sediments of lake Biwa elucidated by stable carbon isotope composition. Geochem. J., 44, 161-166 (2010).

Irwin, R.J., M. VanMouwerik, L. Stevens, M.D. Seese and W. Basham: Environmental Contaminants Encyclopedia. National Park Service, Water Resources Division, Fort Collins, Colorado (1997).

Jin, X., W. Tian, Q. Liu, K. Qiao, J. Zhao and X. Gong: Biodegradation of the benzo[a]pyrene-contaminated sediment of the Jiaozhou Bay wetland using Pseudomonas sp. immobilization. Mar. Pollut. Bull., 117, 283-290 (2017).

Li, X., X. Lin, P. Li, W. Liu, L. Wang, F. Ma and K.S. Chukwukae: Biodegradation of the low concentration of polycyclic aromatic hydrocarbons in soil by microbial consortium during incubation. $J$. Hazard. Mater., 172, 601-605 (2009).

Li, Y., H. Wang, F. Hua, M. Su and Y. Zhao: Trans-member transport of fluoranthene by Rhodococcus sp. BAP-1 and optimization of uptake process. Biores. Technol., 115, 213-219 (2014).

Luch, A.: The carcinogenic effects of polycyclic aromatic hydrocarbons. Imperial College Press, London, UK. ISBN 1860944175 (2005).

Mandal, S.K., A. Selvi and N. Das: A novel approach on degradation of benzo[a]pyrene by yeast consortium isolated from contaminated 
soil. DerPharm. Lett., 8, 80-93 (2016).

Marynowski, L., J. Smolarek, A. Bechtel, M. Philippe, S. Kurkiewicz and B.R.T. Simoneit: Perylene as an indicator of conifer fossil wood degradation by wood-degrading fungi. Org. Geochem., 59, 143151 (2013).

Meng, P., H. Pei, W. Hu, Y. Shao and Z. Li: How to increase microbial degradation in constructed wetlands: influencing factors and improvement measures. Biores. Technol., 157, 316-326 (2014).

Mohan, S.R.V., M.P. Devi, M.V. Reddy, K. Chandrasekhar, A. Juwarkar and P.N. Sarma: Bioremediation of petroleum sludge under anaerobic microenvironment: Influence of biostimulation and bioaugmentation. Environ. Eng. Manage. J., 10, 1609-1616 (2011).

Pérez-Pantoja, D., B. González and D.H. Pieper: Aerobic degradation of aromatic hydrocarbons. In: Handbook of hydrocarbon and lipid microbiology (Eds.: N.K. Timmis). Springer-Verlag, Berlin, pp. 800-837 (2010).

Silva, I.S., M. Grossman and L.R. Durrant: Degradation of polycyclic aromatic hydrocarbons (2-7 rings) under microaerobic and verylow-oxygen conditions by soil fungi. Int. Biodeter. Biodegr., 63, 224-229 (2009).

Mishra, S. and S.N. Singh: Biodegradation of benzo(a)pyrene mediated by catabolic enzymes of bacteria. Int. J. Environ. Sci. Technol., 11, 1571-1580 (2014).

Slater, G.F., A.A. Benson, C.H. Marvin and D.C. Muir: PAH fluxes to Siskiwit revisted: trends in fluxes and sources of pyrogenic $\mathrm{PAH}$ and perylene con-strained via radiocarbon analysis. Environ. Sci. Technol., 47, 5066-5073 (2013).

Wang, J., X. Quan, L. Han, Q. Yia and W. Hegemann: Microbial degradation of quinolone by immobilized cells of Burkholderin pickettii [J]. WaterRes., 36, 2288-2296 (2002).

Winquist, E., K. Björklöf, E. Schultz, M. Räsänen, K. Salonen, F. Anasonye, T. Cajthaml, K.T.S., K.S. Jørgensen and M. Tuomela: Bioremediation of PAH-contaminated soil with fungi - from laboratory to field scale. Int. Biodeter. Biodegr., 86, 238-247 (2014).

Zapien, M.E.R., H.G. Zegarra, N.G. Rojas and L.C. Fernandez: Assessment of hydrocarbon biodegradability in clayed and weathered polluted soils. Int. Biodeter. Biodegr., 63, 347-353 (2009).

Zafra, G., Á.E. Absalón, M.Á. Anducho-Reyes, F.J. Fernandez and D.V. Cortés-Espinosa: Construction of PAH-degrading mixed microbial consortia by induced selection in soil. Chemosphere, 172, 120126 (2017).

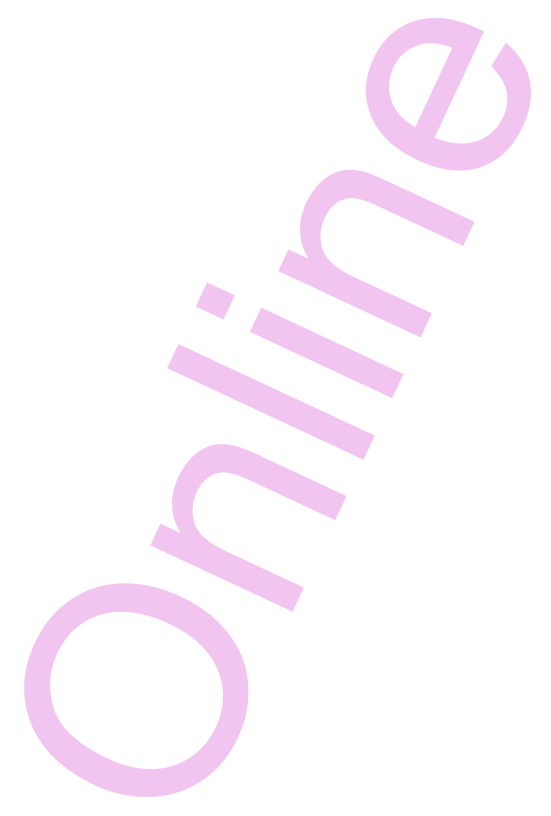

